\title{
La intencionalidad de los directores de fotografía en la evolución de la luz cinematográfica. Desde The kiss in the tunnel hasta Avatar
}

\section{Cinematographers' intention in cinema light historical evolution. From The kiss in the tunnel to Avatar}

\author{
Laura Cortés Selva. Universidad Católica San Antonio
}

Recibido: 4-XII-2013 - Aceptado: 5-IX-2014

Resumen:

La existencia de la cinematografía está condicionada por la luz, cuya capacidad comunicativa revela la expresión del director de fotografía. Aunque existen varios autores que lidian con la misma, no se ha profundizado sobre la intencionalidad de los directores de fotografía proyectada en la luz de las imágenes cinematográficas. De ahí que uno de los objetivos principales de esta investigación se centre en elaborar un recorrido histórico de la luz cinematográfica ejemplificado a través de los filmes más representativos de cada década, y en los que se analiza la intencionalidad de los creadores. En función de ese modo de entender el mundo se realiza una clasificación de los estilos lumínicos, se analizan las consecuencias de la elección de un estilo u otro sobre el filme, y las diferencias entre el estilo europeo y el norteamericano. En este estudio se ha empleado una metodología cualitativa basada en la revisión de las principales fuentes bibliográficas sobre la fotografía cinematográfica y sus principales aplicaciones expresivas, así como en el análisis exhaustivo de las obras fílmicas más relevantes -desde el punto de vista fotográfico- de la historia del cine.

Palabras clave:

Comunicación visual, Luz, Ideología, Tecnología cinematográfica, Fotografía cinematográfica.

Abstract:

Light is determinant for the existence of cinema and its communication ability reveals cinematographers' expression. Although there are several authors dealing with light historical evolution, there has been little reflection upon cinematographers' intentions reflected on cinema pictures. Therefore, one of the goals of this research is focused on offering an historical overview of light evolution through the most representative films of each decade, where cinematographers' intentionality is analyzed. Related to their philosophy, a classification of lighting styles is conducted, as well as analyzed the possible consequences originated from the election of one style or another and the differences between European and North American style. A qualitative methodology has been employed in this study. Based on an in depth review of the main bibliographical sources about cinematography, as well as on an exhaustive analysis of the most relevant feature films -from a photographic point of view-of the cinema history.

Key words:

Visual Communication, Light, Ideology, Cinema Technology, Cinematography.

doxa.comunicación | n 19, pp. 109-130|109 


\section{Introducción}

La existencia de la cinematografía está condicionada por la luz, que además de ser un elemento físico, posee una capacidad comunicativa que revela la expresión artística de los directores de fotografía. La luz cinematográfica es un elemento estilístico desde el que es posible abordar la historia del cine y sobre el que han tratado diferentes autores. No obstante, aunque existen numerosas obras relacionadas con la fotografía cinematográfica, no se ha profundizado sobre la intencionalidad de los creadores proyectada en la luz de las imágenes cinematográficas.

La mayoría de las obras sobre la luz cinematográfica se centran en exclusiva en los aspectos técnicos de la misma (Mascelli, 1998; Brown, 1994 y 2002; Millerson, 1994; Malkiewicz, 1992; Hummel, 2001). Otras fuentes bibliográficas como la revista American Cinematographer-publicada desde 1920 - no sólo están especializadas en el desarrollo tecnológico relacionado con la fotografía cinematográfica, sino en las principales aplicaciones expresivas de dichas innovaciones. Por lo tanto, este tipo de publicación no sólo es una fuente imprescindible para el conocimiento de los desarrollos tecnológicos más relevantes, sino que supone una fuente importante para el estudio de las tendencias expresivas imperantes en el medio cinematográfico en determinadas décadas.

Del mismo modo, se consideran fundamentales los artículos publicados por la Sociedad de Ingenieros del medio cinematográfico y televisivo (JMPTE, Journal of Motion Picture and Television Engineers), y que Fielding (1983) recoge en una de sus obras.

Otros autores no sólo reflexionan sobre el desarrollo tecnológico de la luz cinematográfica a lo largo de la historia del cine, sino que se centran en sus principales aplicaciones estilísticas (Salt, 1992 y 2006; Bordwell, 2007, 2006, 2005 y 1997; Bordwell \& Thompson, 1995; Bordwell, Thompson \& Staiger, 1997).

La relación entre la luz cinematográfica y sus posibles significados son cuestiones sobre las que reflexionan otros investigadores (Metz, 1973; Revault D’Allones, 2003; Russell, 1981; Susperregui, 2004 y 2001), así como la relación entre la técnica y la ideología (Lebel, 1971; Baxter, 1975; Comolli, 2010).

Uno de los objetivos principales de esta investigación se centra en elaborar un recorrido histórico de la luz cinematográfica desde el inicio del cinematógrafo hasta la actualidad, ejemplificado a través de los filmes más representativos de cada década. En ese recorrido se tendrán en cuenta los elementos tecnológicos relacionados con la luz cinematográfica, los resultados visibles en el formato en el que se imprime (película o soporte digital) y se analizará la intencionalidad -en cuanto al tratamiento lumínico- de los directores de fotografía. En función de ese modo de entender el mundo se realiza una clasificación de los estilos lumínicos, se analizan las consecuencias que tiene la elección de un estilo u otro sobre el filme, y si existen diferencias entre el estilo lumínico europeo y el norteamericano.

Para cubrir los objetivos anteriormente expuestos, en esta investigación se ha empleado una metodología cualitativa basada en la revisión de las principales fuentes bibliográficas que versan sobre la fotografía cinematográfica y las aplicaciones 
expresivas más importantes relacionadas con la luz cinematográfica. Del mismo modo, también se ha realizado un análisis exhaustivo del empleo lumínico presente en las obras fílmicas más relevantes -desde el punto de vista fotográfico-de la historia del cine.

A través de la estructura de este estudio se establecen las bases teóricas sobre el director de fotografía y sus competencias como autor en la producción cinematográfica. Del mismo modo, se presenta una síntesis histórica dividida en las décadas que transcurren desde la invención del cinematógrafo hasta el 2010, que trata de ofrecer una visión panorámica del comportamiento lumínico.

A pesar de los riesgos de generalización que conlleva la síntesis de un periodo de tiempo tan vasto, se ha considerado fundamental para ofrecer un marco histórico temporal útil para futuras investigaciones, puesto que ofrece una visión panorámica de las innovaciones relacionadas con la luz cinematográfica y sus principales aplicaciones expresivas.

\section{El director de fotografía, autor de la luz cinematográfica}

El término "Séptimo arte" (Romaguera i Ramió y Alsina Thevenet, 1998: 15-18) se acuña por primera vez en 1911, por Riccioto Canudo. Desde entonces, la dimensión artística del cine es una de sus características esenciales que ha despertado el interés hacia la reflexión sobre la aportación de los individuos que participan en las producciones audiovisuales. Entre los puntos más debatidos en los estudios fílmicos se encuentra la distinción de los elementos que dependen de cada individuo creador. Tradicionalmente estudiado desde el punto de vista del director del filme, el análisis de las aportaciones se ha focalizado -en exclusiva- en su persona centrándose principalmente en los componentes de la puesta en escena.

No obstante, el cine es un arte colaborativo que implica la existencia de una autoría colectiva (collective authorship) (Wright, 2003: 12). Esta característica implica que -aunque el director es el supervisor de la totalidad de la obra- existen otros responsables como el director de fotografía que, a su vez, dirigen a un equipo de personas y disponen de un ámbito de creación sobre el que serían autores. Para conocerlo, más que recurrir a los componentes tradicionales de la puesta en escena, en este estudio se propone la teoría de la práctica cinematográfica (Cortés-Selva, 2013: 26) que presupone el conocimiento previo de las funciones que cada individuo creador desempeña en un filme.

Las competencias del director de fotografía incluyen tanto el campo técnico como el artístico, y su labor consiste en crear -junto al director- la visualización cinematográfica de modo coherente con la narración (Vaccano, http://www.aecdirfot.org/biblio/dirfotol.htm). Para ello, se responsabiliza de los parámetros técnicos y artísticos relacionados con la captación de las imágenes: la luz, la composición visual y los movimientos de cámara. Por lo tanto, el director del filme da el visto bueno, pero la ideación y consecución de la fotografía cinematográfica de un filme pertenece a la expresión artística del director de fotografía. 
La iluminación cinematográfica incluye el conjunto de luces existentes en un espacio susceptible de ser fotografiable, y que es parte fundamental de la dirección de fotografía cinematográfica (Susperregui, 2004).

En el inicio de la trayectoria lumínica que incluye la preproducción, la producción y la postproducción y visionado de la imagen cinematográfica, el director de fotografía concibe un planteamiento conceptual sobre el esquema lumínico que se reflejará en el filme. La luz -de ese modo- funciona como soporte de su expresión artística: en la que proyecta las ideas que pretende transmitir.

En la fase de producción, la concepción lumínica creada por el director de fotografía se proyecta sobre un objeto-sujeto y/o espacio, que a su vez la refleja. La creación lumínica que se proyecta sobre los objetos y sujetos en un espacio, no existiría más que en ese momento si no se registrara en un soporte sensible o en un sensor.

Lo más habitual es utilizar una cámara cinematográfica que regule la entrada de la luz reflejada por los objetos y/o sujetos, a través de la óptica cinematográfica. La luz atraviesa un sistema de lentes y alcanza el soporte en el que se imprime o registra la información. En la fase de postproducción, los ojos del espectador captan la imagen proyectada en una pantalla a través del fenómeno de la "persistencia retiniana", produciendo la ilusión del movimiento.

\section{La evolución de la luz cinematográfica}

"By its very presence, light expresses the 'inner essence' of all vision, because, even at the moment of perception, it exhausts any further ideas we might have of it” (Baxter, 1975: 102).

En este apartado se realiza una evolución histórica de la luz cinematográfica por décadas y por orden cronológico, ejemplificada a través de las obras más representativas. El primer apartado expone la evolución lumínica desde los inicios del cine hasta la década de los veinte. El siguiente se centra en la década que recorre desde los años veinte hasta los treinta, para -a continuación- introducirnos en el periodo que oscila desde el final de la segunda Guerra Mundial hasta los años sesenta. A partir de la década de los sesenta y hasta el 2010 se suceden una serie de capítulos que incluyen los años setenta, ochenta y noventa, hasta el 2010.

\subsection{The kiss in the tunnel. La luz inexpresiva de los comienzos del desarrollo cinematográfico}

"The conventions of lighting which were to dominate Hollywood production up to the present day had more or less been arrived at by 1918; there were important technical advances still to be made, but dominant ideology behind lighting would remain that of revelation and expression" (Baxter, 1975: 100).

The kiss in the tunnel (G.A. Smith, 1899) o L’Affaire Dreyfus (Georges Mèliés, 1899) son algunos de los ejemplos característicos de este periodo histórico que muestran que, la luz presente en los filmes de principios de la historia del cine no se 
caracterizan por poseer una intencionalidad narrativa concreta, sino que su objetivo es el correcto visionado de la imagen fílmica. La baja sensibilidad del celuloide ${ }^{1}$ implica la necesaria presencia de una gran cantidad de luz para impresionar el material sensible, lo que supone que los rodajes primitivos se realicen con luz diurna, tanto en los espacios o localizaciones exteriores como en los platós primitivos (Revault D’Allones, 2003: 44).

Poco después de la invención del cinematógrafo surgen los platós con techos y paredes de cristal -como el pionero Black María de Edison- que provocan que la luz natural cenital sea una constante en los filmes de la época. Por su parte, Mèliés creará en 1897, un nuevo plató que permite abrir y cerrar el techo e incorpora telas de algodón para suavizar la dureza de la luz solar (Salt, 1992: 31-39), lo que supone un primer intento por controlar la luz.

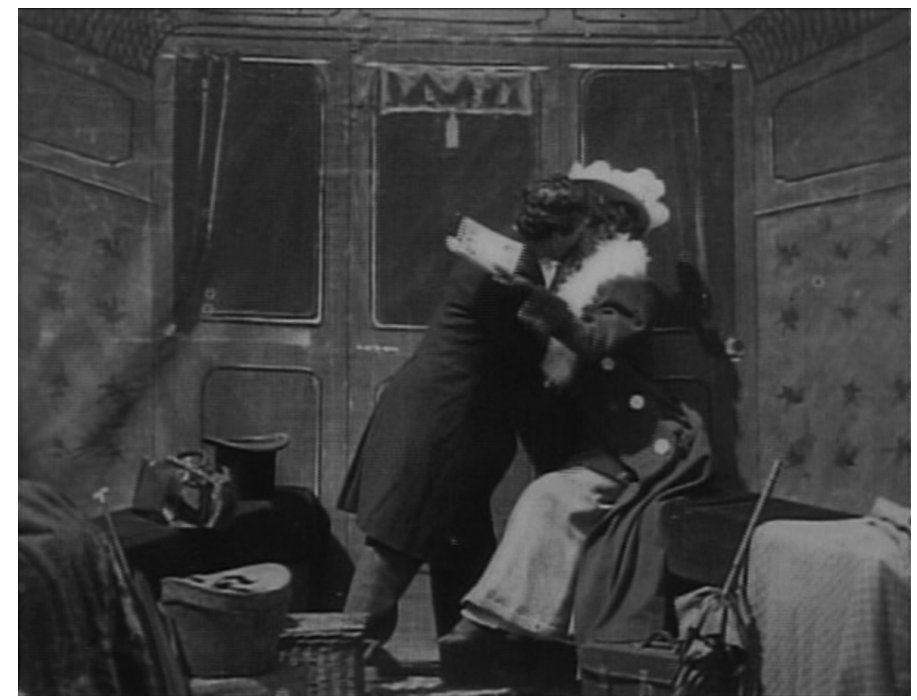

The kiss in the tunnel (G. A. Smith, 1899)

La introducción de la luz artificial en los platós a principios del siglo XX es de gran importancia porque permite aplicar el concepto de iluminación cuando se habla de la luz en el cine. Empleada en un principio como apoyo o refuerzo de la luz natural, la artificial se convierte -posteriormente- en la fuente de luz principal.

En un principio, la iluminación no tiene otro propósito que el de impresionar el negativo, pero hacia 1905 aparecen algunos efectos expresivos aunque la mayoría son producto de la casualidad (Salt, 1992: 63-91). Ejemplos de estos efectos se

1 Durante los primeros años del desarrollo del cinematógrafo se emplea el celuloide ortocromático (no sensible al espectro electromagnético que abarca la zona roja-anaranjada) en blanco y negro, y con una reducida sensibilidad (oscila entre los 6 y los 8 ASA al principio, y posteriormente alcanza los 20 ASA). 
encuentran en filmes como Oliver Twist (J. Stuart Blackton, 1909) o Ved Faengslets Port (August Blom, 1911) fotografiada por Axel Graatkjaer.

La aparición de la luz de contra o contraluz constituye otro de los desarrollos importantes en esta etapa. Junto con la luz frontal forman el principio de la luz de modelado o esculpido, técnica que incluye una luz principal, una de relleno y un contraluz (esquema de tres puntos), que se sitúan en ángulos diferentes según su intensidad, la posición del actor y su fisonomía. También se combina el doble contraluz con una luz principal y otra de relleno (esquema de cuatro puntos), aunque es una técnica menos habitual.

\subsection{Scaramouche. La estandarización de la luz durante la década de los veinte}

La estandarización del estilo básico lumínico (basado en los esquemas de tres y de cuatro puntos) presente en filmes como Scaramouche (Rex Ingram, 1923) fotografiada por John F. Seitz, sucede en la década de los veinte, especialmente en filmes realizados en Hollywood en los que no se producen cambios apreciables en la evolución lumínica (Salt, 1992: 181-182).

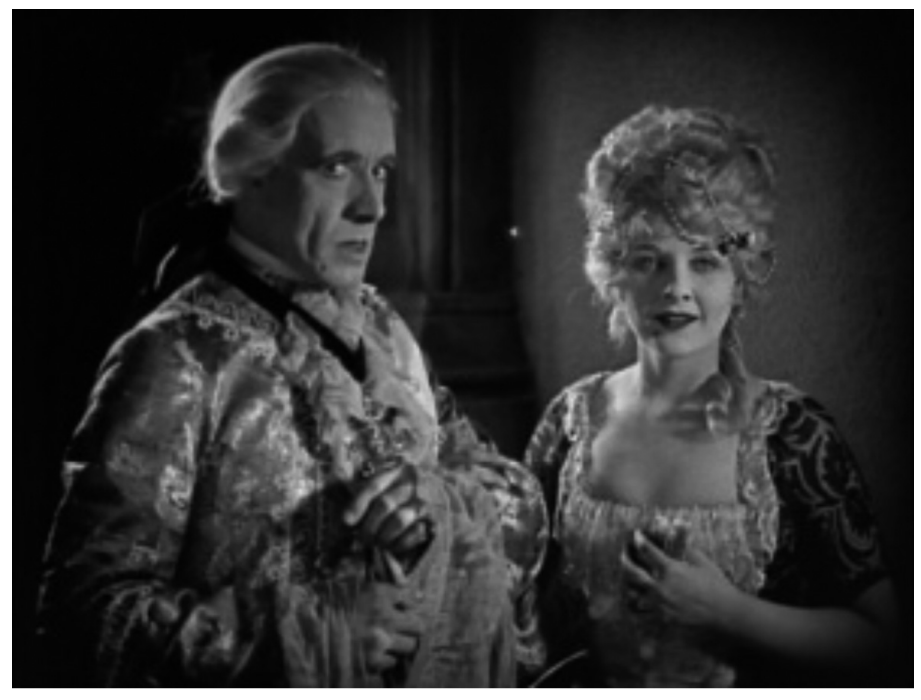

Scaramouche (Rex Ingram, 1923)

A principios de la década de los años veinte, en Estados Unidos, la mayoría de los platós tienen restringida la entrada de la luz natural y por lo tanto, trabajan en exclusiva con la luz artificial. Esta característica es contraria a la práctica presente en los platós europeos en los que se evidencia la presencia de la luz natural. 
La introducción de un proyector lumínico -denominado arco- capaz de concentrar y/o dispersar el haz de luz es una de las novedades más destacables de esta época. Su presencia será característica de las producciones hollywoodienses de principios de los años 20 como The four horsemen of the Apocalypse (Rex Ingram, 1921) fotografiada por John F. Seitz, o He who gets slapped (Victor Sjöstrom, 1924), fotografiada por Milton Moore, ya que su haz de luz direccional, intenso y duro permite controlarlo con facilidad (Revault D`Allones, 2003: 47).

El diseño de una luz general cenital (proporcionada por los proyectores Cooper-Hewitt que se colocan suspendidos del techo o desde plataformas en el suelo), y una luz dura, direccional que define las siluetas (proporcionada por los proyectores arco) supone el esquema lumínico básico presente en los platós estadounidenses de la época.

La sombra constituye un elemento expresivo que forma parte de la naturaleza de la luz cinematográfica. En Europa, con las propuestas estéticas del expresionismo alemán se populariza su empleo, así como el de la luz en clave baja. Entre los filmes más representativos se encuentran Das Cabinet des Dr. Caligari (Robert Wiene, 1920), Genuine (Robert Wiene, 1920), Von Maorgens bis Mitternacht (Karl-Heinz Martin, 1920), Torgus (Hans Kobe, 1921), Raskolnikov (Robert Wiene, 1923) y Das Wachsfigurenkabinett (Paul Leni, 1924) y de alguna manera Metrópolis (Fritz Lang, 1926).

Los directores de fotografía que emigran a Estados Unidos como Karl Freund, colaborador del director de cine F.W. Murnau en Alemania, con quien dirige la influyente Der Letzte Mann (F.W. Murnau, 1924), ejercen una influencia decisiva en los filmes norteamericanos de la primera mitad de la década de los cuarenta (Zubiaur, 1999: 102). Entre los ejemplos encontramos el caso de Gregg Toland, director de fotografía de Citizen Kane (Orson Welles, 1941), quien recibe una gran influencia del citado director de fotografía.

\subsection{Shanghai Express. La luz adiestrada de los grandes estudios cinematográficos en la década de los treinta}

"The distinction of the star is the distinction of the hero or the saint; the aura which surrounds the exceptional being becomes in the cinema as in portraiture an actual aura, a special emanation that marks the vibrancy of the heoric-stellar space" (Baxter, 1975: 103).

Durante la década de los treinta, en Estados Unidos, los grandes estudios como la Metro Goldwyn Mayer (MGM), la Warner Bros. y la Fox definen su propio estilo fotográfico caracterizado por la utilización de un celuloide con unas especificaciones, de un tipo de iluminación y de una determinada apertura de diafragma. La MGM se caracteriza por un estilo propio de las comedias, claro y luminoso (high-key) presente en filmes como Grand Hotel (Edmund Goulding, 1932), fotografiada por William H. Daniels o Smillin`Through (Sidney Franklin, 1932), fotografiada por Lee Garmes. Frente a ello se sitúa el estilo dramático proporcionado por el claroscuro (low-key) de la Warner (Chion, 1992: 198), presente en filmes como Little Caesar (Mervyn LeRoy, 1931), fotografiada por Tony Gaudio o The public enemy (William A. Wellman, 1931), fo- 
tografiada por Devereaux Jennings. Para la consecución de sus objetivos, los estudios contratan en exclusiva a los directores de fotografía a los que imponen su estilo visual. Esta filosofía anula su creatividad al imposibilitarles el desarrollo de su propio estilo, y los convierte en meros ejecutores sustituibles entre sí. La metodología planteada por los estudios cinematográficos llega al extremo de concebir esquemas basados en una jerarquía lumínica que ensalza a la estrella principal, en términos de brillo lumínico, la destaca sobre el resto de elementos visuales sin importar la coherencia con la narración. Este sistema obliga a los actores a limitar su actuación a las marcas de luz colocadas en el suelo, lo que provoca que -en ocasiones- los actores vean imposibilitado su trabajo. Shanghai Express (Josef Von Sternberg, 1932) fotografíado por Lee Garmes, es uno de los filmes representativos de la citada jerarquía lumínica.

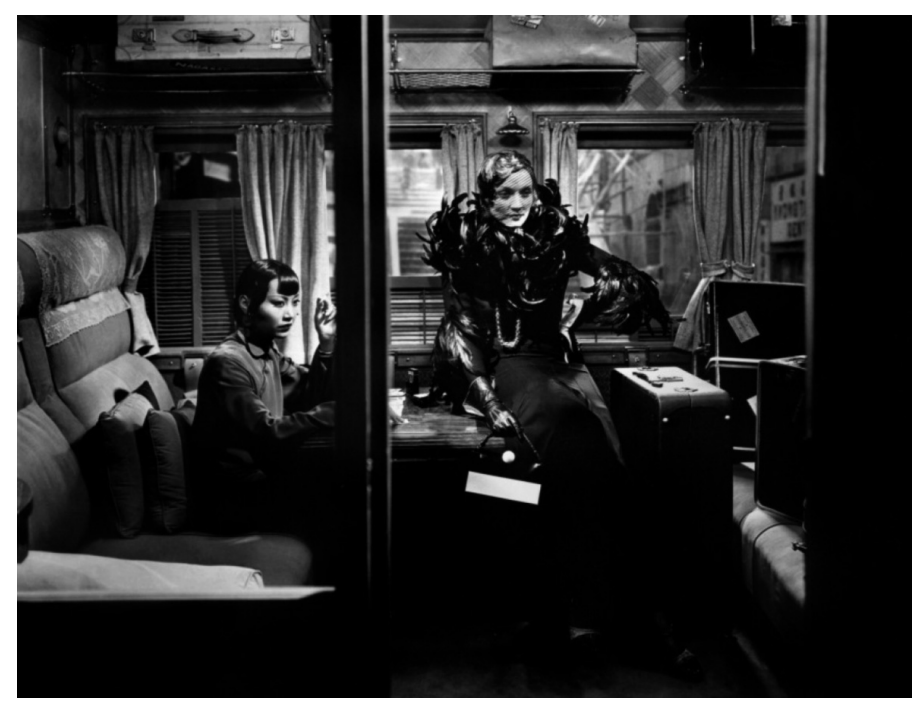

Shanghai Express (Josef Von Sternberg, 1932)

La aparición en 1934 de las lentes de cristales concéntricos denominadas Fresnel, permite ejercer un gran control sobre la luz, lo que es fundamental para lograr este tipo de resultado.

\subsection{Jules et Jim. La liberación de la luz: 1945-1960}

Entre las causas que explican la presencia del planteamiento realista en filmes pertenecientes a esta etapa se encuentra el desarrollo -durante la Segunda Guerra Mundial- del trabajo de una gran cantidad de directores de fotografía en películas documentales y de ficción. Para entender los cambios estilísticos introducidos en este periodo es de gran importancia considerar la voluntad ética y estética, tras la contienda, de las personas involucradas en la producción de los filmes. La 
búsqueda de la verdad provoca la creación de planteamientos lumínicos cercanos al documental. La luz se libera y vuelve a sus orígenes, pero esta vez de modo consciente.

El tratamiento realista está presente en el cine ruso de la década de los veinte, con directores como Sergei Eisenstein, Igor Pudovkin o Dziga Vertov. También en Francia con representantes como Jean Renoir, o en la escuela británica de los años treinta. No obstante, uno de los movimientos más importantes de este periodo es el neorrealismo italiano, cuyos filmes comparten el mismo estilo visual que los documentales (VV. AA., 2003: 49-51). Características similares concurren en los filmes herederos del neorrealismo, las nuevas olas que surgen en diferentes países de Europa, entre las que destaca la Nouvelle Vague francesa, que provoca una ruptura en el estilo fotográfico de los filmes. Entre los directores de fotografía que forman parte de este movimiento se encuentran Raoul Coutard -quien dirige la fotografía de Jules et Jim (François Truffaut, 1962)- Henri Decaë -director de fotografía de quien Les quatre cents coups (François Truffaut, 1959)-, o Néstor Almendros.

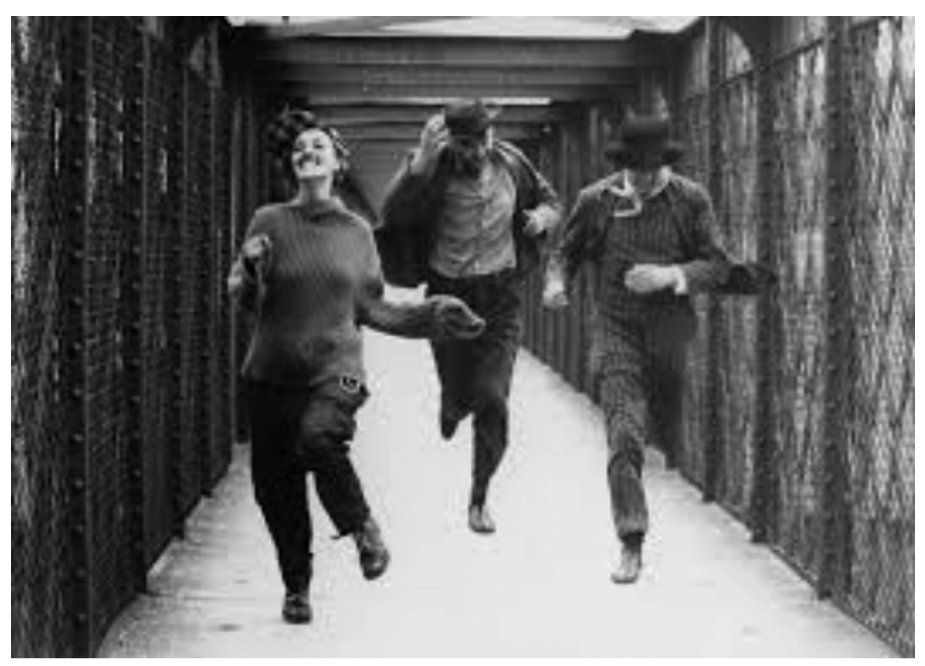

Jules et Jim (François Truffaut, 1962)

El estilo de la Nouvelle Vague se decanta por la utilización de la luz natural que -en ocasiones- mezcla con la artificial. Aprovechan las fuentes de luz natural presentes en las localizaciones o las recrean artificialmente enfatizando en especial la reflexión de la luz. Una de las prácticas más habituales en el estilo de iluminación de esta etapa es la obtención de una luz suave y envolvente sin sombras pronunciadas. El resultado visual se aproxima a lo que posteriormente se ha denominado "luz del norte", es decir, el tipo de efecto que provoca la luz natural al introducirse en un espacio a través de una ventana orientada al norte. 
Lo que parece ser el descubrimiento de un esquema de iluminación más verosímil, ofrece serios problemas relacionados con la obtención de una imagen sin volumen, que compromete su expresividad. El director de fotografía Néstor Almendros es uno de los pioneros en apuntar dicha problemática, así como la necesaria búsqueda de soluciones más expresivas. De ahí que ciertos directores de fotografía apoyen el estilo de iluminación que hibrida la reflexión de la luz con otras fuentes de iluminación más direccionales que enfatiza el volumen de la imagen y la enriquecen.

A pesar de la existencia desde los años veinte de la tradición realista, y aunque ciertas obras como The Grapes of Warth (John Ford, 1940), fotografiada por Gregg Toland, comienzan a decantarse por un estilo más realista, en Estados Unidos prevalece el férreo sistema de normas impuesto por los estudios.

\subsection{Cleopatra. La justificación y la continuidad lumínica como característica de la década de los sesenta}

"As part of the ideological production of dominant cinema, light, which was technically necessary for sheer perception, was to be 'naturalised' in accordance with the example of Dutch art that is, given source and direction" (Baxter, 1975: 102).

Aunque existen ciertas tentativas en cuanto a la introducción de novedades en el estilo lumínico con la finalidad de obtener un mayor realismo, la gran mayoría de los filmes producidos durante esta década conservan el mismo paradigma que en la anterior, es decir, una versión simplificada de los esquemas de luz imperantes en los años cuarenta. Por lo tanto, las renovaciones estilísticas procedentes de Europa no influyen en la fotografía cinematográfica norteamericana de esta década. 


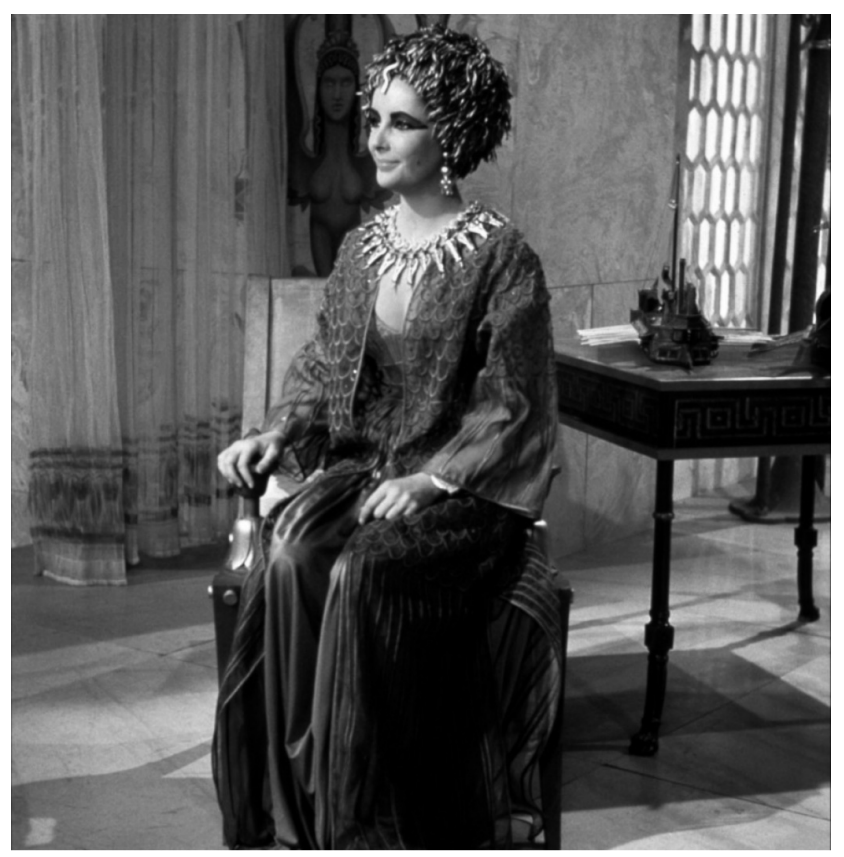

Cleopatra (Joseph L. Mankiewicz, 1963)

A pesar de contribuir a la falta de verosimilitud de los films, los directores de fotografía que continúan en activo en el panorama norteamericano de esta década siguen desarrollando trabajo en los platós, bajo circunstancias controlables. Esta predilección por el rodaje en los estudios está ligada -en palabras de Comolli (2010)- a razones práctico económicas, históricas (herencia del cine mudo), e ideológicas (preocupación por la perfección técnica). No obstante, en esta etapa existe una inquietud por buscar una mayor veracidad en el estilo visual de las imágenes resultantes. Surge el concepto de la justificación de las fuentes de luz (source lighting) presente en filmes como Cleopatra (Joseph L. Mankiewicz, 1963), fotografiada por Leon Shamroy, o My fair lady (George Cukor, 1964), fotografiada por Harry Strading. Supone la creación de esquemas de luz artificial que imiten a las fuentes de luz natural, pero también el aprovechamiento de los fenómenos naturales que iluminan el espacio fotografiable (ventanas, apliques, lámparas de pie, etc.). En ocasiones, la luz natural es el único medio de iluminación o la base a partir de la cual se refuerza con métodos artificiales. La justificación de las fuentes de luz está estrechamente relacionada con el concepto de continuidad lumínica o raccord de luz, que consiste en la obtención de valores lumínicos similares entre planos contiguos (dirección de la luz, contraste, brillo y colorimetría), que permite una continuidad o coherencia narrativa en el estilo visual de los filmes (American Cinematographer, 1966: 768). 


\subsection{The graduate. Tendencias renovadoras de los años setenta: el abandono de la luz de la vieja escuela}

Brian De Palma, Terrence Malick, Woody Allen, Robert Altman, Francis Ford Coppola, Steven Spielberg o Martin Scorsese son algunos de los directores de cine que surgen a finales de la década de los sesenta y setenta, interesados en investigar nuevas formas de narrativa visual. Con la colaboración de varios directores de fotografía que comienzan a despuntar en este periodo ${ }^{2}$ huyen de las imposiciones de los grandes estudios y se inclinan hacia un estilo lumínico más realista, en el que se abandona la luz dura y se justifican las fuentes de luz. De este modo, surgen un conjunto de obras que comparten ciertos atributos comunes y que determinados autores denominan el "nuevo Hollywood" o el "renacimiento de Hollywood" (Bordwell, Thompson \& Staiger, 1985: 417). Entre ellas se encuentran The graduate (Mike Nichols, 1967), fotografiada por Robert Surtees; Easy rider (Dennis Hopper, 1969), fotografiada por Laszlo Kovacs; The long goodbye (Robert Altman, 1973), fotografiada por Vilmos Zsigmond; Taxi Driver (Martin Scorsese, 1976) o Days of heaven (Terrence Malick, 1978), fotografiada por Néstor Almendros.

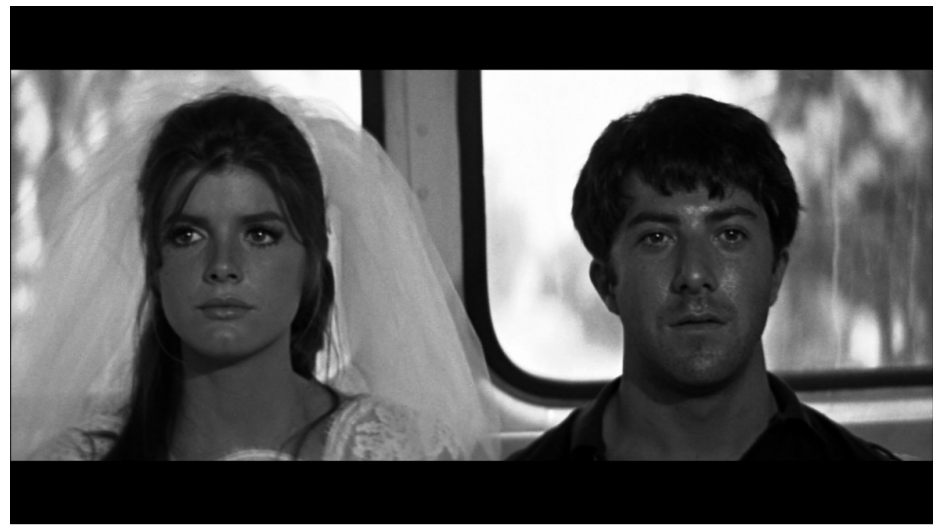

The graduate (Mike Nichols, 1967)

Mediante los métodos empleados por estos autores se logra un tipo de obra que redefine el concepto de verosimilitud, con una estética próxima a la presente en los filmes de la Nouvelle Vague. De hecho, Jules et Jim (François Truffaut, 1962), fotografiada por Raoul Coutard, es una de las obras que causa una mayor influencia entre los directores de fotografía norteamericanos de la época.

2 Con el relevo generacional comienzan a sobresalir figuras de gran importancia para la fotografía cinematográfica internacional, como los norteamericanos Gordon Willis, William A. Fraker, Conrad L. Hall, Haskell Wexler, Michael Chapman y Owen Roizman; los británicos Oswald Morris, Geoffrey Unsworth y John Alcott; el italiano Vittorio Storaro, el sueco Sven Nykvist y los húngaros Vilmos Zsigmond y Laszlo Kovacs, entre otros. 
El clima de renovación imperante en EE.UU provoca que, en esta década, ciertos directores de fotografía introduzcan técnicas cinematográficas incorrectas desde el punto de vista clásico, que contribuyen a aportar una mayor verosimilitud al relato fílmico. Entre ellas, destaca la utilización del lenguaje expresivo de la sombra que el director de fotografía Gordon Willis idea para el filme The Godfather (Francis Ford Coppola, 1972). La dirección cenital de la luz proyecta zonas en sombra que imposibilitan la correcta visibilidad de la expresión de los ojos de los protagonistas, y provoca en el espectador una sensación incómoda de ocultación de la verdad.

Otras prácticas que se alejan del tratamiento clásico y que ofrecen resultados más verosímiles son la utilización de la luz procedente de fuentes presentes en el decorado o practicables (velas, linternas, faroles, lámparas, tubos fluorescentes, etc), así como la mezcla de diferentes temperaturas de color de la luz. Uno de los primeros filmes en los que se detecta es The French Connection (William Friedkin, 1971), fotografiada por Owen Roizman (American Cinematographer, 1972: 211).

Entre los directores de fotografía que emplean fuentes de luz artificial pero no desean alejarse de la realidad, una de las tendencias imperantes en esta década es la consolidación de un tipo de luz suave. Las grandes dimensiones y la potencia de las fuentes de luz presentes en este periodo posibilitan su colocación a mayores distancias de la acción principal, obteniendo resultados más naturales puesto que la dirección de la luz se hace invisible. Este planteamiento se considera el siguiente paso en la evolución de la iluminación suave heredada de los directores de fotografía europeos, y está presente en filmes como Il Conformista (Bernardo Bertolucci, 1970) o Last Tango in Paris (Bernardo Bertolucci, 1972), ambas fotografiadas por Vittorio Storaro.

\subsection{Blade Runner. El look especial como marca de autor de la década de los ochenta}

Durante esta década se produce una alta hibridación de los diferentes estilos lumínicos relacionada con la internacionalización de los creadores cinematográficos. Esta circunstancia provoca que la diferencia entre los conceptos "cine europeo" y "cine americano" se diluya, y sea más conveniente sustituirlos por el término genérico "cine del mundo" (world cinema) (Elsaesser, 2005: 485-511).

En esta década comienza la búsqueda de nuevas propuestas visuales que superen la estética del periodo moderno a través de la construcción de una imagen atractiva que capte la atención del espectador. La tendencia hacia la narración auto-consciente se verá reflejada en la creación de un estilo visual o look especial, una especie de "marca" de autor (Bordwell, 2006: 152-154).

Las propuestas realistas siguen presentes a través del trabajo de directores de fotografía como Miroslav Ondricek en Amadeus (Milos Forman, 1984) (Lee, 1985: 94-101); Robby Müller en París, Texas (Wim Wenders, 1984); Sven Nykvist en Fanny och Alexander (Ingmar Bergman, 1982) (Block, 1984: 50-58); o Néstor Almendros en Heartburn (Mike Nichols, 1986) (Wiener, 1986: 36-42). 
Las propuestas presentadas por la vertiente formalista plantean esquemas lumínicos en los que la luz no está necesariamente justificada y en los que se produce un retorno a los esquemas clásicos de iluminación de tres y de cuatro puntos. Entre las muestras del retorno a los planteamientos más clásicos se encuentra la recuperación de la luz de contra o contraluz (con iluminación dura), presente en películas como Flashdance (Adrian Lyne, 1983), fotografiada por Donald Peterman (Veze, 1983: 72-76, 109-113) y Blade Runner (Lightman \& Patterson, 1982: 720-724).

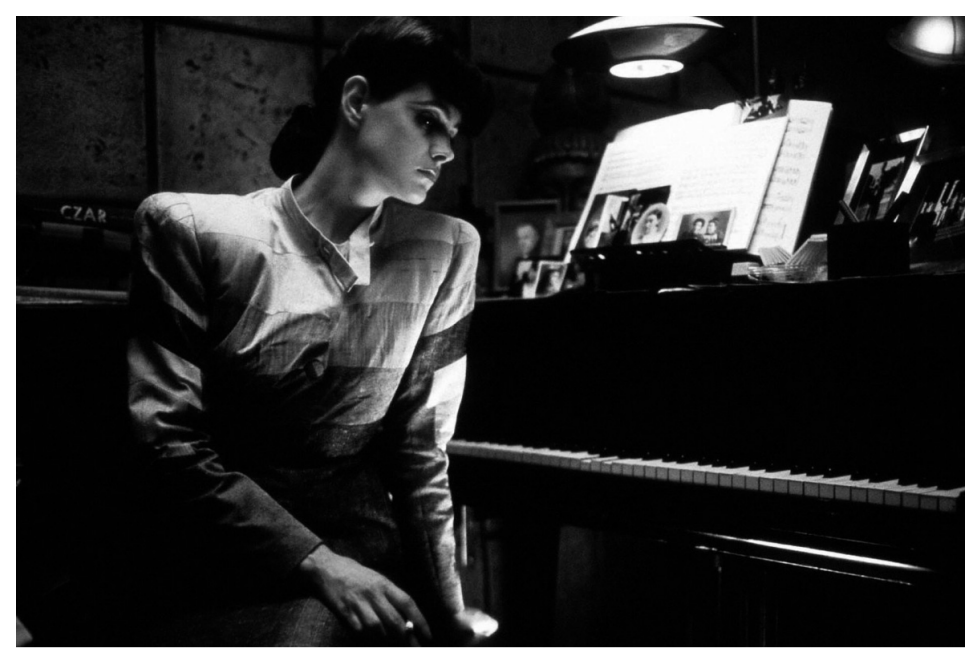

Blade Runner (Ridley Scott, 1982)

Dentro de la vertiente formalista, una de las tendencias que aparece a finales de la década de los setenta y que se consolida en las posteriores es el trabajo presente en Alien (Ridley Scott, 1979), fotografiada por Derek Vanlint (Vanlint, 1979: 768-771, 806, 812-813). Dominada por un esquema de luz en clave baja, dura y contrastada, con grandes dosis de sub-exposición, los filmes empiezan a ser sensiblemente más oscuros. Emplea algunos métodos de iluminación inusuales que no poseen justificación en las fuentes de luz natural, para crear una atmósfera que marca el tono del filme. La influencia de Alien está presente en obras posteriores como Blade Runner (Ridley Scott, 1982), fotografiada por Jordan Cronenweth; Star Wars: The Empire strikes back (Irvin Kershner, 1980) fotografiada por Peter Suschitzky; Lost Highway (David Lynch, 1996) fotografiada por Peter Deming (Pizzello, 1997: 34-42); o Crash (David Cronenberg, 1996) por Peter Suschitzky (Daviau \& Elmes, 1997: 39). 


\subsection{Natural Born killers y Breaking the waves. El extremismo de las propuestas lumínicas de la década de los noventa}

El estilo lumínico que prevalece durante la década de los noventa es una prolongación del periodo anterior. La diferencia más sobresaliente entre los dos decenios radica en el extremismo presente en las propuestas estilísticas que ciertos autores de los noventa aplican a sus obras.

La narración auto-consciente que Noël Carroll (1998: 261) define como "estilización estridente" (strident stylization), continúa durante este periodo. Entre los casos más significativos de la presencia del extremismo entre las propuestas formalistas, se encuentran los filmes realizados por el director Oliver Stone y el director de fotografía Robert Richardson, en filmes como The Doors (Oliver Stone, 1991), JFK (Oliver Stone, 1991), Natural Born Killers (Oliver Stone, 1994) y U-Turn (Oliver Stone, 1997) (Gentry, 1996: 37).

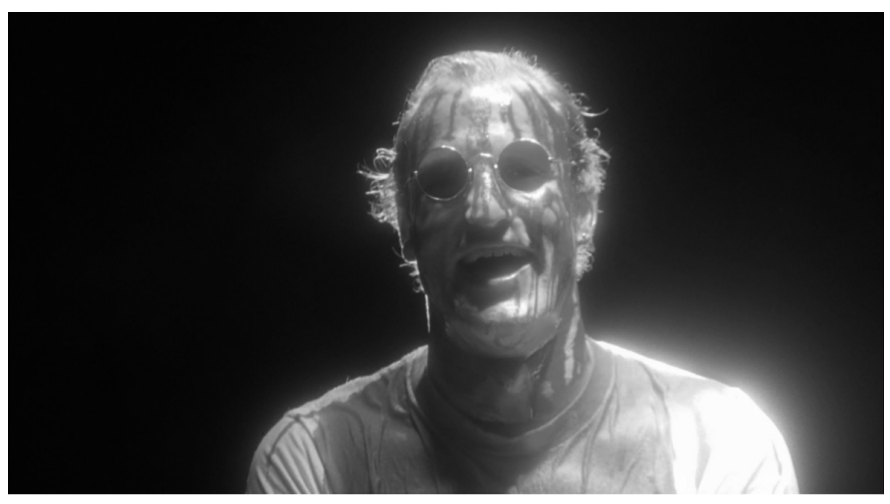

Natural Born Killers (Oliver Stone, 1994)

En la vertiente realista, destaca el surgimiento del movimiento Dogma '95 a finales de los noventa. Liderado por el cineasta Lars Von Trier, sus principios estéticos poseen su origen en las vanguardias de cine europeo de mediados de los años cincuenta y sesenta, así como en los documentales. Reivindica un cine alejado del artificio de Hollywood, que transmita la máxima verosimilitud, para lo que se adscribe de modo voluntario a una serie de normas entre las que destaca un tratamiento lumínico que no significa, la ausencia de la luz artificial y de cualquier dispositivo técnico de embellecimiento de la imagen. Breaking the Waves (Lars Von Trier, 1996) fotografiada por Robby Müller, es uno de los primeros filmes que promulgan el estilo Dogma'95. Siguiendo un planteamiento similar, y de modo más radical, se encuentran propuestas visuales que son iconos que el espectador asocia con el máximo realismo, como las videograbaciones de aficionados o home movies. The Blair Witch Project (Daniel Myrick y Eduardo Sánchez, 1999) fotografiada por Neal Fredericks, es uno de los filmes en los que está presente esta estética. 


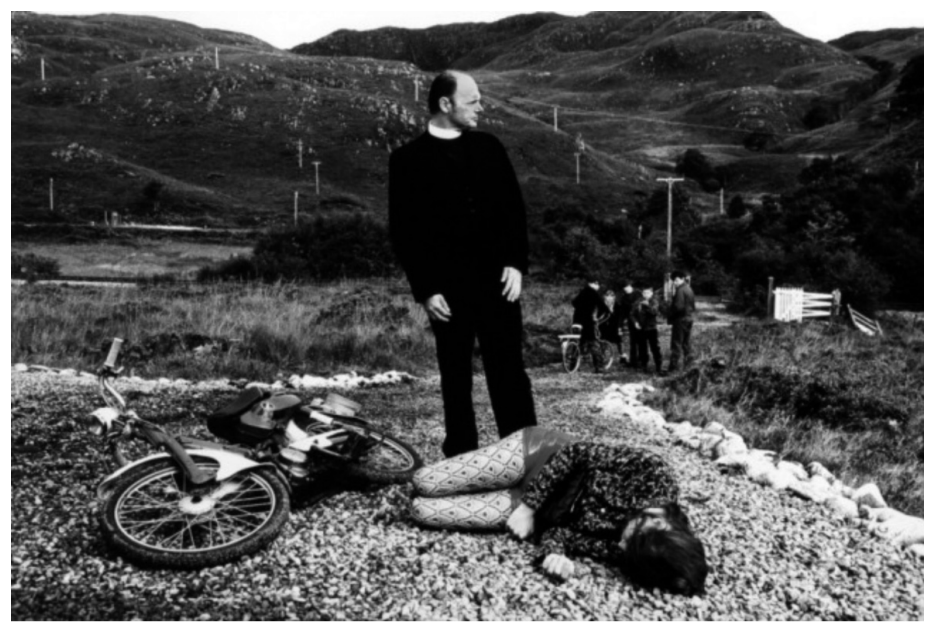

Breaking the Waves (Lars Von Trier, 1996)

\subsection{Avatar. La posproducción digital, transformadora de la luz cinematográfica y creadora de la luz virtual}

Durante la etapa comprendida entre el 2000 y el 2010, continúa un gran extermismo en las vertientes formalista y realista, cuyo objetivo principal sigue siendo la búsqueda de imágenes atractivas que capten la atención del espectador de un modo más agresivo.

Destacan en especial en esta época, las propuestas de la vertiente realista en las que se detecta la presencia de la puesta en escena documental. Denominada estilo vèrité por su relación con el cinema vèrité, persigue un resultado de gran autenticidad con imágenes que simulan estar sucediendo en tiempo real para provocar en el espectador la vivencia directa de la acción. Su estilo se aleja de los mecanismos clásicos de la ilusión cinematográfica con planteamientos lumínicos que optan por la luz natural, muda, que no significa, y prescinde de la luz artificial o la reduce al mínimo. Se pretende que las imágenes muestren aquello que observan nuestros ojos sin actuar sobre ellas ni introducir artificios, lo que en principio resume la filosofía vèrité. Entre los ejemplos destacan los filmes Elephant (Gus Van Sant, 2003) fotografiada por Harris Savides (Thomson, 2003: 60-71); Children of Men (Alfonso Cuarón, 2006) fotografiada por Emmanuel Lubezki (Bergery, 2006: 62 y 70); Milk (Gus Van Sant, 2008), fotografiada por Harris Savides (Oppenheimer, 2008: 34); Paranoid Park (Gus Van Sant, 2007), fotografiada por Christopher Doyle (Davis, 2008: 20) o The Wrestler (Darren Aronofsky, 2008) (Walla, 2009: 22 ).

El Intermedio Digital (Digital Intermediate o DI), surge a finales de la década de los noventa. Se trata de un proceso en el que está involucrado el escaneado del negativo, su manipulación mediante plataformas digitales, y su impresión posterior en una emulsión sensible. Este proceso híbrido (celuloide-digital-celuloide) es el paso intermedio de la transición de 
un sistema analógico a otro digital, y convierte el celuloide en un soporte similar al de la paleta y el lienzo de un pintor, ya que ofrece la posibilidad de manipular la imagen por áreas independientes, entre ellas la la luz.

Entre los filmes que muestran de modo pionero las posibilidades del dispositivo se encuentra O brother, where art thou (Joel Coen, 2000) fotografiada por Roger Deakins. En este filme, a través del tratamiento selectivo de la imagen, se logra imitar el estilo visual de las postales antiguas pintadas a mano de los años treinta (Fisher, 2000: 36-49).

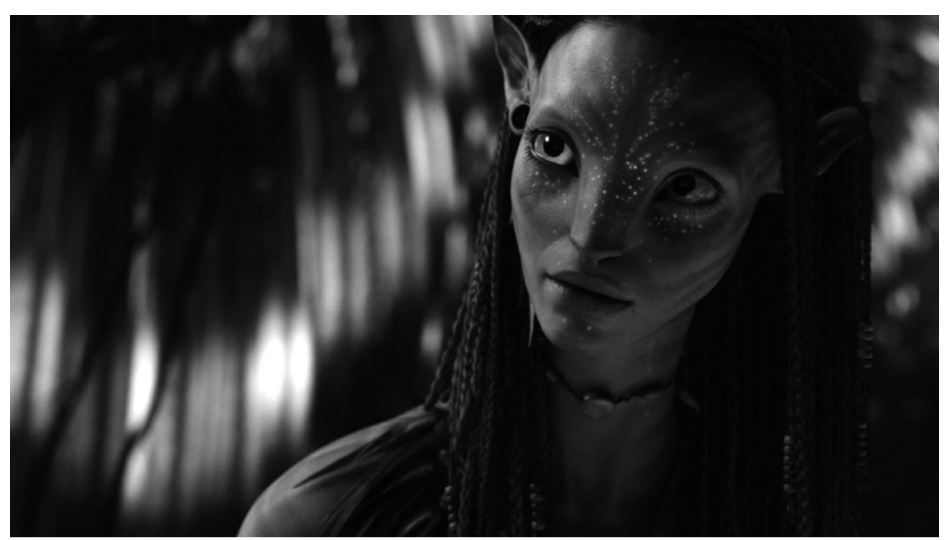

Avatar (James Cameron, 2009)

Durante esta década, fruto de la introducción y el desarrollo de los sistemas digitales, surge la luz virtual (Argy, 2001: 8089 y 2005: 94-99). Creada por los iluminadores virtuales en imágenes generadas por ordenador, este tipo de luz puede estar presente en la totalidad de un largometraje o en algunas escenas. Aunque en ciertas producciones no es necesario justificar las fuentes de luz debido al tipo de narración, en aquellos casos en los que sí es necesario, para crear la luz virtual los iluminadores toman como referente la luz real o la presente en otros productos audiovisuales. En el caso de las narraciones en las que se combinan imágenes generadas por ordenador con otras captadas de la realidad, los iluminadores virtuales tratan de imitar el trabajo de los directores de fotografía.

Este tipo de luz virtual supone el control máximo sobre la luz cinematográfica, muy superior al logrado a través de la manipulación de las fuentes de luz artificial tradicionales. Entre algunos ejemplos encontramos filmes como Sin City (Frank Miller, Robert Rodríguez y Quentin Tarantino, 2005), fotografiada por Robert Rodríguez, o Avatar (James Cameron, 2009), fotografiada por Mauro Fiore. 


\section{Conclusiones}

Llegados a este punto es hora de arrojar algunas conclusiones. Entre ellas, comenzar con que es posible realizar una recorrido histórico de la luz cinematográfica ejemplificado a través de los filmes más representativos de cada década. Desde The kiss in the tunnel hasta Avatar, dichas imágenes reflejan los diferentes niveles de intencionalidad de los directores de fotografía que revelan una forma de entender el mundo. Dicha filosofía permite realizar una clasificación de los directores de fotografía y de los estilos que crean a través de su proyección sobre la imagen cinematográfica.

La intencionalidad de los directores de fotografía ha estado condicionada por los desarrollos tecnológicos y por el conocimiento del lenguaje lumínico (ambos muy pobres en los inicios del cine). El dominio del lenguaje de la luz provoca que aumente su control hasta alcanzar sus cotas más altas durante los años 30 y 40, especialmente en Estados Unidos, lo que provoca una estandarización del estilo lumínico. Frente al panorama descrito, tras la II GM, los directores de fotografía europeos -aunque también conocedores del lenguaje lumínico- optan por ejercer un menor control sobre la luz, la liberan creando un estilo diferente. Dicha intencionalidad influye en Estados Unidos especialmente a partir de la década de los setenta. Con la internacionalización de los creadores a partir de la década de los ochenta, los directores de fotografía comienzan a intensificar la hibridación de sus propuestas lumínicas, y encontramos más creadores que mezclan una luz libre con otra controlada.

Por lo tanto, la historia de la evolución lumínica y de las intenciones de los directores de fotografia nos muestra que, prácticamente desde los inicios, existen tres estilos lumínicos: el formalista, el realista y el que hibrida a ambos.

El estilo formalista incluye a los directores de fotografía que quieren controlar la imagen desde el principio al fin. Entienden la forma cinematográfica no como un soporte para crear una mímesis de la naturaleza, sino como una oportunidad para crear un mundo propio, elaborar un discurso en el que el resultado sea previsible, controlado y preciso. Para ello, emplean la luz artificial -no necesariamente justificada- ya que la verosimilitud no es una característica prioritaria. Se trata de una luz a disposición del creador que es consciente de los resultados expresivos que obtiene. Existe una predisposición hacia el rodaje en los estudios, lo que pone de manifiesto preocupaciones relacionadas con el control lumínico y la perfección técnica, así como una actitud de inmediatez en los resultados.

Entre los filmes que se pueden incluir en este estilo destacan Sleepy Hollow (Tim Burton, 1999) fotografiada por Emmanuel Lubezki, Goya en Burdeos (Carlos Saura, 1999), fotografiada por Vittorio Storaro o Moulin Rouge! (Baz Luhrmann, 2001), fotografiada por Donald McAlpine.

En el estilo realista se incluyen a aquellos directores de fotografía que tratan de imitar la realidad otorgando una mayor libertad a la luz natural. Están abiertos a la obtención de resultados visuales no tan previsibles como los formalistas, en busca de una mayor verosimilitud. Esta luz más libre implica una actitud de espera y un mayor riesgo para el director de fotografía porque el control sobre la misma es inferior. 
Entre las opciones que contempla el estilo realista existe un primer caso en el que la luz es inexpresiva e inconsciente, propia de productos como los documentales, las noticias o los reportajes. Entre esta aproximación se encuentran propuestas que defienden el uso exclusivo de la luz natural sin intervenir sobre ella mediante ningún dispositivo artificial. Es la luz natural, inexpresiva, presente en un espacio susceptible de rodaje, propia de productos audiovisuales como los reportajes, los documentales o las noticias, en los que el pacto con el espectador es de máxima verosimilitud.

Una segunda opción contempla la luz inexpresiva pero consciente, propia de filmes que tratan de imitar el estilo visual de los documentales, los reportajes o las noticias, empleando elementos estilísticos a su alcance, entre los que se encuentra la luz natural sin manipular. Dicha luz, en ese caso, es consciente y expresiva porque existe una intención de comunicar algo a través de su empleo.

Una tercera opción trata con una luz expresiva y consciente, propia de filmes que buscan un momento lumínico concreto para transmitir una atmósfera determinada. Sucede en aquellos filmes que buscan un momento determinado del día para rodar una escena o la película completa. Es el caso del director de fotografía Néstor Almendros, quien para el rodaje de ciertas escenas de Days of Heaven (Terrence Malick, 1978), espera al intervalo lumínico comprendido entre la puesta de sol y su ocultación total (“hora mágica”) para conseguir un efecto atmosférico concreto.

El tercer estilo contemplado incluye a aquellos directores de fotografía que hibridan las opciones realista y formalista. Trata de crear una imagen verosímil, no muy alejada de la realidad, en la que se mezclan la luz natural y la artificial pero siempre trata de justificarlas teniendo como modelo a la realidad. Es una luz expresiva y consciente sobre la que se ejerce diferentes niveles de control, ya que en ocasiones es trabajada, manipulada y en otras se deja libre, por lo que se mezcla la actitud de espera y de inmediatez.

Los tratamientos lumínicos de esta tendencia incluyen aquellos en los que se manipula la luz natural mediante elementos artificiales (superficies reflectoras, espejos, pantallas, etc.), aquellos en los que se mezcla la luz natural y la artificial, y los que contemplan la justificación de las fuentes de luz.

Por diferentes motivos -entre los que se encuentra el económico- el realismo lumínico se asocia más con la tradición europea frente al formalismo vinculado al estadounidense. No obstante, esa diferenciación comienza a diluirse a partir del surgimiento de las nuevas olas europeas, momento en el que empieza una hibridación estilística que se hace plenamente consciente a partir de los años ochenta, cuando se diluyen las fronteras entre el cine europeo y el americano. La alta hibridación de los estilos lumínicos ofrece un extremismo en las propuestas realista y formalista que afecta a ambos continentes, y que pretende -por un lado- llamar la atención del espectador y -por otro- suscitar que lo narrado está sucediendo en tiempo real. De ahí que aunque las consecuencias de la elección de un estilo u otro en principio no son ni positivas ni negativas sino que son el resultado de una ética y una estética, tanto un exceso de control sobre el resultado 
visual como su escasez pueden ser negativas. Un control lumínico excesivo que no tenga en cuenta el contenido narrativo puede conducir a una imagen sin coherenia con la narración en la que prevalezca exclusivamente lo formal. Por su parte, la falta de control puede conducir a una imagen en la que-sin pretenderlo- la luz no tenga ninguna intención y pierda su esencia como elemento del lenguaje cineamatográfico.

\section{Referencias bibliográficas}

American Cinematographer (1972): "Photographing The French Connection”, American Cinematographer, vol. 53, n. 2, February.

American Cinematographer (1966): "Directional continuity in motion picture photography", American Cinematographer, vol. 47, n. 11, November.

Argy, S. (2005): “Post focus: Improvements in virtual lighting”, American Cinematographer, vol. 86, n. 12.

Argy, S. (2001): "Painting with virtual light”, American Cinematographer, vol. 82, n. 3.

Baxter, P. (1975): “On the history and ideology of film lighting”, Screen, vol. 16, n. 3, pp. 88-106.

Bergery, B. (2006): “Humanity’s last hope”, American Cinematographer, vol. 87, n. 12.

Block, B. (1984): "Academy Awards Nominees: Sven Nykvist, ASC and Fanny \& Alexander", American Cinematographer, vol. 65, n. 4.

Bordwell, D. (2007): Poetics of cinema. New York: Routledge.

Bordwell, D. (2006): The way Hollywood tells it: Story and Style in modern movies. Berkeley and Los Angeles: University of California Press.

Bordwell, D. (2005): Figures traced in light: On cinematic staging. Berkeley \& Los Angeles: University of California Press.

Bordwell, D. (1997): On the history of film style. Cambridge, MA: Harvard University Press.

Bordwell, D. \& Thompson, Kr. (1ª edición 1995): El arte cinematográfico. Barcelona: Paidós Comunicación Cine.

Bordwell, D.; Thompson, K. \& Staiger, J. (1ª edición 1997): El cine clásico de Hollywood: Estilo cinematográfico y modo de producción hasta 1960. Barcelona: Paidós Comunicación.

Brown, B. (2002): Cinematography: Theory and practice: image making for cinematographers, directors and videographers. London: Focal Press.

Brown, B. (1994): Iluminación en cine y televisión. San Sebastián: Escuela de cine y vídeo.

Canudo, R. (1998): Manifiesto de las siete artes, en Romaguera i Ramió, Joaquim y Alsina Thevenet, Homero: Textos y manifiestos del cine. Madrid: Ediciones Cátedra. 
Carroll, N. (1998): Interpreting the moving image. Cambridge: Cambridge University Press.

Chion, M. (1992): El cine y sus oficios. Madrid: Cátedra.

Comolli, J. L. (2010): Cine contra espectáculo seguido de técnica e ideología (1971-1972). Buenos Aires: Ediciones Manantial.

Cortés Selva, L. (2013): "Principales aplicaciones expresivas derivadas de la hibridación analógico-digital. El estilo visual realista”, Archivos de la Filmoteca, n. 72, pp. 23-35.

Daviau, A. y Elmes, F. (1997): “Auto erotic”, American Cinematographer, vol. 78, n. 4.

Davis, B. (2008): “Production slate: Indie drama and horror”, American Cinematographer, vol. 89, n. 4.

Elkins, M. (1984): “Steven Spielberg on Indiana Jones and the temple of doom”, American Cinematographer, vol. 65, n. 7.

Elsaesser, T. (2005): European cinema: Face to face with Hollywood. Amsterdam: Amsterdam University Press.

Fielding, R. (1983): A Technological History of Motion Pictures and Television. Berkeley: University of California Press.

Fisher, B. (2000): “Escaping from chains”, American Cinematographer, vol. 81, n. 10.

Gentry, R. (1996): “A splintered vision of America”, American Cinematographer, vol. 77, n. 3.

Hummel, R. (ed.) (2001): American Cinematographer manual. Hollywood: ASC Press.

Lebel, J. P. (1971): Cinéma et ideologie. París: Editions Sociales.

Lee, N. (1985): “Miroslav Ondricek and Amadeus”, American Cinematographer, vol. 66, n. 4.

Lightman, H. A. y Patterson, R. (1982): “Blade Runner, production design and photography”, American Cinematographer, vol. 63, n. 7 .

Malkiewicz, K. (1992): Cinematography: A guide for filmmakers and film teachers. New York: Fireside book.

Mascelli, J. V. (1998): The five C's of cinematography. Los Angeles: Silman-James Press.

Metz, C. (1973): Lenguaje y cine. Barcelona: Editorial Planeta.

Millerson, G. (1994): Iluminación para televisión y cine. Madrid: Instituto Oficial de Radio y Televisión Española.

Oppenheimer, J. (2008): “A high price for progress”, American Cinematographer, vol. 89, n. 12.

Pizzello, C. (1997): “Highway to hell”, American Cinematographer, vol. 78, n. 3.

Revault D’Allones, F. (2003): La luz en el cine. Madrid: Cátedra.

Russell, S. A. (1981): Semiotics and lighting: a study of six french cameramen. Michigan: UMI Research Press.

Sammon, P. M. (1984): “John Hora and Gremlins”, American Cinematographer, vol. 65, n. 11. 
Salt, B. (2006): Moving into pictures. London: Starword.

Salt, B. (1992): Film style and technology: History \& Analysis. London: Starword, 2a edición.

Susperregui, J. M. (2004): La fotografía como interfaz cinematográfico: La importancia de la luz en el discurso cinematográfico. Actas II Congreso Ibérico de Comunicación.

Susperregui, J. M. (2001): “La linealidad de la luz: la comunicación visual moderna”, Zer, n. 10, vol. 6, pp. $177-193$.

Thompson, A. (1995): "Trains, Veins and Heroin Deals", American Cinematographer, vol. 77, n. 8.

Thomson, P. (2003): “Walking the halls of fate”, American Cinematographer, vol. 84, n. 10.

Vaccano, J.: http://www.aecdirfot.org/biblio/dirfotol.htm [Consultado el 20/03/2014].

Vanlint, D. (1979): “Alien and its photographic challenges”, American Cinematographer, vol. 60, n. 8.

VV. AA. (2003): Making Pictures: A century of European cinematography. London: Aurum Press Ltd.

Veze, R. (1983): Photography for Flashdance”, American Cinematographer, vol. 64, n. 5.

Walla, C. (2009): “Production slate: On the ropes”, American Cinematographer, vol. 90, n. 22.

Wiener, D. (1986): “Straight shooting for Heartburn”, American Cinematographer, vol. 67, n. 8.

Wright, V. (ed.) (2003): Film and Authorship. New Brunswick. New Jersey and London: Rutgers University Press Depth of field series. 